\title{
Trilhas de pesquisas: práticas tecnológicas do patrimônio cultural
}

\author{
Research trails: technological practices of cultural heritage
}

Laís Soares Pereira Simon, Alexandre Amorim dos Reis, Flávio Anthero Nunes Vianna dos Santos

Metodologia, tecnologia, patrimônio cultural

A cibercultura, com suas funções, acaba tendo um papel muito grande de socialidade, usando a tecnologia digital contemporânea como instrumento de novas formas de vínculos profissionais, associativos e comunitários que nos aproximam também da memória virtual e do patrimônio digital. O uso de metodologias e ferramentas tecnológicas para o patrimônio, oferece à humanidade a oportunidade de ampliar o conceito de patrimônio e difundir as informações da herança cultural, principalmente pelo surgimento de novos métodos para identificação das informações e novos modos de documentação do patrimônio cultural. A partir disso, este artigo apresenta um estudo exploratório, em que foi realizado um levantamento de práticas metodológicas e tecnológicas atualmente utilizadas por pesquisadores e profissionais do setor do patrimônio cultural, principalmente arquitetônico e artístico, a fim de direcionar pesquisas nesse campo.

Methodology, technology, cultural heritage

Cyberculture with its functions ends up playing a very large role of sociality, using contemporary digital technology as an instrument of new forms of professional, associative and community bonds that also bring us closer to virtual memory and digital heritage. The use of methodologies and technology tools for heritage offers humanity the opportunity to expand the concept of heritage and disseminate information about cultural heritage, mainly due to the emergence of new methods for identifying information and new ways of documenting cultural heritage. Based on this, this article presents an exploratory study, in which a survey of methodological and technological practices currently used by researchers and professionals in the cultural heritage sector, mainly architectural and artistic, was carried out in order to direct research in this field.

\section{Introdução}

O comportamento da sociedade urbana contemporânea vem passando por mudanças provocadas pelas revoluções nas mídias e no processo da distribuição da informação, pela inserção das tecnologias de informação e comunicação. Lucia Santaella (2003), aponta as diferenças entre a cultura das mídias e a cultura digital, sobretudo pelo fato de que a cultura das mídias trata de uma convivência entre as diferentes mídias, que podem ser: televisão, rádio, jornal, livros, entre outros. A cultura digital proporciona uma convergência, ou seja, possibilita concentrar todas as informações, tanto de texto, som, imagem e vídeo, em um mesmo lugar e com uma mesma linguagem principalmente devido à capacidade de

Anais do $10^{\circ} \mathrm{CIDI}$ e $10^{\circ} \mathrm{CONGIC}$

Kelli C.A.S. Smythe, Rafael de Castro Andrade (orgs.) Sociedade Brasileira de Design da Informação - SBDI Curitiba | Brasil | 2021
Proceedings of the $10^{\text {th }} \mathrm{CIDI}$ and $10^{\text {th }}$ CONGIC

Kelli C.A.S. Smythe, Rafael de Castro Andrade (orgs.)

Sociedade Brasileira de Design da Informação - SBDI Curitiba | Brazil | 2021 
digitalização, compressão, manipulação, armazenamento, reprodução e distribuição de forma digital e em um único suporte.

Com a popularização e desenvolvimento da internet e das cibercidades, o cotidiano está cada vez mais em um território virtualizado, isto é, ampliando a espacialidade da interface da tela do computador para recobrir todos os espaços naturais, sobrepondo o ciberespaço ao próprio espaço físico. Como esse lugar eletrônico passou a ser uma extensão dos lugares físicos, logo essas alterações devem refletir sobre a expansão do patrimônio cultural, que vem sendo apropriado por esse ambiente ubíquo, do senciente e do pervasivo, juntamente com a informação (AZEVEDO, 2020) modificando, assim, a forma como as pessoas estão e veem o mundo. Por meio dessa intersecção entre patrimônio, informação e o contexto atual, as tecnologias podem ser utilizadas como ferramentas na preservação e mudanças de paradigmas, sendo possível oferecer novas experiências no universo dos objetos, conjuntos, sítios e edificações de interesse para a preservação.

Nesta circunstância, a tecnologia pode apoiar o incremento da percepção dos espaços históricos, principalmente pela grande possibilidade de disseminação de conhecimento e informações visuais. Estas, por sua vez, são excepcionais ferramentas de colaboração, valorização e construção de memória, pois possibilitam um meio para a documentação, publicação e divulgação do patrimônio construindo, assim, um novo olhar e formas de apropriação sobre os bens culturais, uma vez que a memória do passado é um patrimônio que sedimenta o conjunto de decisões do presente e os projetos futuros.

O desenvolvimento das possibilidades oferecidas pelas tecnologias, tem sido explorado em conferências que reúnem pesquisadores, arquitetos e restauradores de vários países do mundo. Seus trabalhos exploraram conceitos e reflexões advindos do campo da virtualidade, porém o resultado são produções espalhadas e visam fatores culturais locais.

Vale ressaltar que muitas equipes e obras de conservação e restauro ainda não acompanham o desenvolvimento e o avanço das possibilidades oferecidas pelas inovações. Observa-se uma desconformidade com o que tem sido absorvido pelos profissionais, empresas e os órgãos de preservação.

Com isso, este estudo pretende fazer um levantamento de práticas metodológicas e tecnológicas que, atualmente, vem sendo empregadas por pesquisadores e profissionais do setor do patrimônio cultural, principalmente arquitetônico e artístico, a fim de direcionar pesquisas nesse campo. Tendo em vista que a tecnologia da ciência da conservação e restauração sempre esteve mais próxima da área da química, agora com as sucessivas mudanças das revoluções nas mídias e no processo de distribuição de informações da atual sociedade contemporânea, faz-se com que a área do patrimônio busque estender seu território para o mundo híbrido da cibercultura.

Dessa forma, é importante levantar as ferramentas tecnológicas e metodológicas que auxiliam as investigações complementares às abordagens físicas e físico-químicas. Esses recursos recentes podem modificar a conduta do campo do patrimônio, possibilitando uma 
melhora nas análises entre as escalas temporais que integram os dados da conservação, restauração e da história dos bens e edificações de valor histórico, cultural e artístico.

\section{Procedimentos metodológicos}

Este trabalho se constitui como uma pesquisa exploratória, em fontes de dados secundários, a fim de adquirir uma familiaridade com o enfoque temático das investigações a respeito de práticas tecnológicas e metodológicas para o levantamento de dados do patrimônio arquitetônico e artístico. A partir desta pesquisa, então, objetiva-se possibilitar documentar, salvaguardar e compartilhar o patrimônio de uma maneira mais acessível e atualizada.

O método de abordagem utilizado, por suas características e objetivos, inclui coleta de informações bibliográficas do grupo francês UMR 3495 CNRS / MC MAP e apresenta este nome por ser uma unidade de pesquisa conjunta, reunindo o Centro Nacional de Pesquisa Científica, Ministério da Cultura e Comunicação da França e equipes das escolas superiores nacionais de arquitetura de Lyon, Nancy, Marselha e Paris La Villette. O perfil desse grupo de pesquisa formou-se em torno do desenvolvimento e implementação de métodos e ferramentas relacionadas com as novas tecnologias de informação e comunicação. São associados arquitetos, engenheiros, historiadores, cientistas da computação e cientista da conservação.

Para sistematizar todas as informações, este artigo adota a proposição que o patrimônio cultural é compreendido em três etapas. Começando com o tombamento, que é primeira etapa de proteção do bem, e assim, seguem as próximas etapas, que são: os processos científicos de documentação, reconstrução digital e catalogação dos bens. O último estágio, é a disseminação das informações para os profissionais e público em geral.

O tombamento é um instrumento jurídico para a proteção do patrimônio cultural, em nível federal, estadual e/ou municipal, por intermédio de órgãos que, reconhecendo o valor cultural de um bem, estabelecem critérios para sua proteção, através de aplicação de legislação específica para bens de valor histórico, cultural, arquitetônico, ambiental e também de valor afetivo para a população, impedindo que venham a ser destruídos ou descaracterizados. A instituição do tombamento pode ser considerada como a prática mais significativa da política de preservação federal no Brasil e, por isso, deve ser citado pela sua relevância nas práticas preservacionistas (ABRANTES, 2014).

As próximas etapas, compreendem o patrimônio cultural e a organização deste estudo, serão abordadas ao longo do artigo e serão apresentadas as ferramentas que possibilitaram desenvolver os estágios dois e três, acima citados.

\section{Processos científicos da conservação e restauro}

Para realizar os processos científicos de documentação, reconstrução digital e catalogação foi necessário o reconhecimento do contexto geral da metodologia da área patrimonial.

A demanda social do trabalho de conservação e restauro de patrimônio histórico-cultural 
ocorre de acordo com as orientações e a regulamentação da Carta de Restauro de 06 de abril de 1972 do Governo da Itália, circular n. ${ }^{\circ} 117$, que determina:

\begin{abstract}
A realização do projeto para a restauração de uma obra arquitetônica deverá ser precedida de um exaustivo estudo sobre o monumento, elaborado de diversos pontos de vista (que estabeleçam a análise de sua posição no contexto territorial, dos aspectos tipológicos, das elevações e qualidades formais, dos sistemas e caracteres construtivos etc.), relativos à obra original, assim como os eventuais acréscimos ou modificações. Parte integrante desse estudo serão pesquisas bibliográficas, iconográficas e arquivísticas, para obter todos os dados históricos possíveis. O projeto se baseará em uma completa observação gráfica e fotográfica, interpretada também sob o aspecto metrológico, dos traçados reguladores e dos sistemas proporcionais e compreenderá um cuidadoso estudo específico para a verificação das condições de estabilidade. (IPHAN, 1972, p. 9).
\end{abstract}

O início de qualquer intervenção no patrimônio começa com o levantamento histórico e imagético dos bens patrimoniais. Remontar a história da edificação histórica é parte de seu conhecimento, identificando os seus materiais, cores e aspectos construtivos e arquitetônicos, além de elementos que anteriormente existiam e que não estão mais presentes. Portanto, em qualquer estudo ou intervenção a respeito do patrimônio edificado, é necessário um levantamento arquitetônico. Esse levantamento serve como documento histórico e consiste no registro gráfico do imóvel construído, a partir da tomada de medidas das fachadas, ambientes e detalhes construtivos essenciais à leitura do edifício.

Este processo de levantamento arquitetônico tem levado a estudos de novas tecnologias, visando a compatibilização dos projetos, redução de tempo e erros. Para isso, as simulações da construção no meio virtual, com novos modelos de modelagem da informação, mostram-se eficiente para a automação de tarefas anteriormente consideradas impossíveis para as máquinas. Além disso, a modelagem da informação da construção surge como alternativa para a gestão do processo de projeto de restauração e preservação do patrimônio, viabilizando a identificação das incompatibilidades entre as especialidades de projeto e facilitando o processo de construção ou recuperação.

A partir destes esclarecimentos projetuais ficou claro como o levantamento arquitetônico foi influenciado pela cultura digital, que abriu novas fronteiras. Com isso, serão apresentados métodos que poderão auxiliar na geração de novos dados, que orientaram na preservação da memória arquitetônica e na gestão de facilidades, mas também no resgate das informações projetuais de edificações, cujo registro se perdeu no tempo. Os métodos pesquisados seguem abaixo.

\title{
Processo BIM (Building Information Modeling)
}

Entre as mudanças possibilitadas pelas tecnologias digitais, estão os softwares que trabalham a plataforma BIM. É uma tecnologia que atende a crescente demanda por uma base de conhecimento multidisciplinar, essencial para gestão de projetos de edificações patrimoniais, principalmente por contribuir para o agrupamento das relações complexas entre a parte material e imaterial dos bens. 
A plataforma BIM permite a reconstrução do bem ou a construção de modelos digitais, compostos por banco de dados que agregam informações para diversas finalidades. Para incremento de outras ferramentas integradas de levantamento ou até mesmo o aumento da produtividade, permitindo assim a racionalização do processo de projetos. Este processo de construção parte de modelos tridimensionais que podem ser realocados em um só modelo integrado, paramétrico, intercambiável e passível de simulação. Além disso, o método de trabalho deixa as plataformas de desenho bidimensionais tradicionais para alimentar um protótipo em software que carrega informações além da geometria (CANUDO \& SALGADO, 2016).

Vale salientar que no território brasileiro, com o vigor do decreto n. ${ }^{\circ} 9377$ em maio de 2018, a plataforma BIM se tornou uma estratégia nacional para incentivar o uso dessa tecnologia. A partir de 2021, a modelagem 3D será exigida para a elaboração de projetos de arquitetura e engenharia. Atualmente, somente $9,2 \%$ das empresas do setor da construção utilizam a modelagem em seus projetos (FUNDAÇÃO GETÚLIO VARGAS apud FARIAS, 2019).

Em resumo, a plataforma BIM traz melhorias ao processo e gestão das obras a partir da visualização completa do projeto, integração da informação, detecção de erros, controle de gastos, logística, medição do tempo de obra, redução de retrabalho e, por fim, diminuição de arquivos gerados. Por ainda não ser um sistema utilizado amplamente, a incompatibilidade e o tamanho dos arquivos gerados são um empecilho entre os profissionais que integram o projeto. Porém, é necessário investir na aquisição de softwares e treinamentos para a aprendizagem da plataforma.

\section{Captura de realidade}

$\mathrm{Na}$ área de preservação do patrimônio histórico, testemunha-se o aumento do uso de ferramentas que permitem a captura da realidade dos bens edificados para fins de levantamento, diagnóstico, documentação, mas, também, em interação com outras tecnologias da área de engenharia e construção civil. O objetivo maior é auxiliar na reconstrução precisa das edificações e, consequentemente, análise e interpretação dos dados.

Essas reconstruções digitais formam modelos de informação da construção, servindo, então, tanto como documento quanto como representação as built - que nada mais é do que representações técnicas de plantas, corte e fachadas com as alterações existentes em uma edificação.

Para esse fim, de representações e seus possíveis desdobramentos futuros, foram pesquisadas ferramentas para auxiliar esses métodos de aquisição de documentos e imagens, conforme abaixo.

\section{Ortofotogrametria}

O levantamento de espaços, para fins de diagnóstico de conservação, muitas vezes é dificultado pelas extensões das áreas e a dificuldade de acesso. As soluções atuais contam com instalações de andaimes que não atendem às necessidades de aproximação e leitura do espaço. As ferramentas contemporâneas permitem uma orientação e posicionamento 
extremamente precisos de veículos voadores não tripulados (drones), para levantar e mapear essas áreas (figura 1). Com o auxílio de dispositivos ópticos por ortofoto documentação, no qual é possível a obtenção de informações sobre objetos físicos e o ambiente circundante através de processos de registro, medição e interpretação de imagens fotográficas, formadas por energias eletromagnéticas produzidas por raios de luz de diferentes pontos (luz direta e termografias).

Esta técnica permite obter uma ótima distribuição espacial dos pontos de vista, portanto, uma melhor regularidade dos fatores de sobreposição inter e intra imagens. Dessa forma, favorece a calibração das câmeras e o refinamento do cálculo de sua posição e orientação no espaço, para, então, implementar protocolos de pilotagem e controle assistidos ou automatizados para a realização de leituras parietais internas.

Figura 1 - Levantamento de pintura mural com ortofotogrametria e auxílio de drone. (Fonte: UMR 3495 CNRS / MC MAP, 2020).

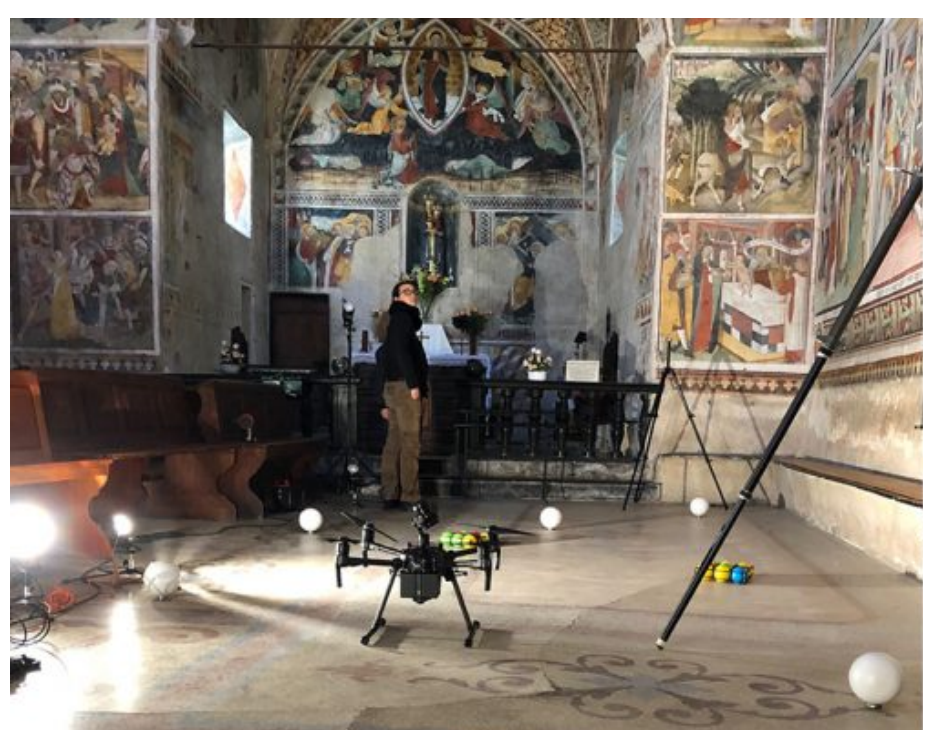

\section{Fotomodelagem}

A fotomodelagem é o resultado da revolução digital que influenciou os artefatos de nossa cultura, desde imagens até ferramentas de interpretação e design, e pode ser considerada um desenvolvimento da fotogrametria. O processo de fotomodelagem, portanto, assume a sua forma a partir da seleção correta de quadros fotográficos e assim envolve cada quadro para compreender seu novo significado de matriz digital de dados numéricos (figura 2). As imagens fotográficas não devem se limitar apenas à área de exame, os frames não devem estar muito distantes uns dos outros e seria interessante seguir um caminho semicircular com fotos a cada $15-30^{\circ}$. Em vista disso, a materialização do modelo é realizada por meio da comparação entre os dados com base na geometria, na qual sustenta os princípios da fotogrametria monoscópica e a posição e gerenciamento de cada pixel da fotografia, caracterizado por uma cor que determina a textura do modelo (FILIPPUCCI, 2011). 
Figura 2 - Representação de fotomodelagem. (Fonte: FILIPPUCCI, 2011).

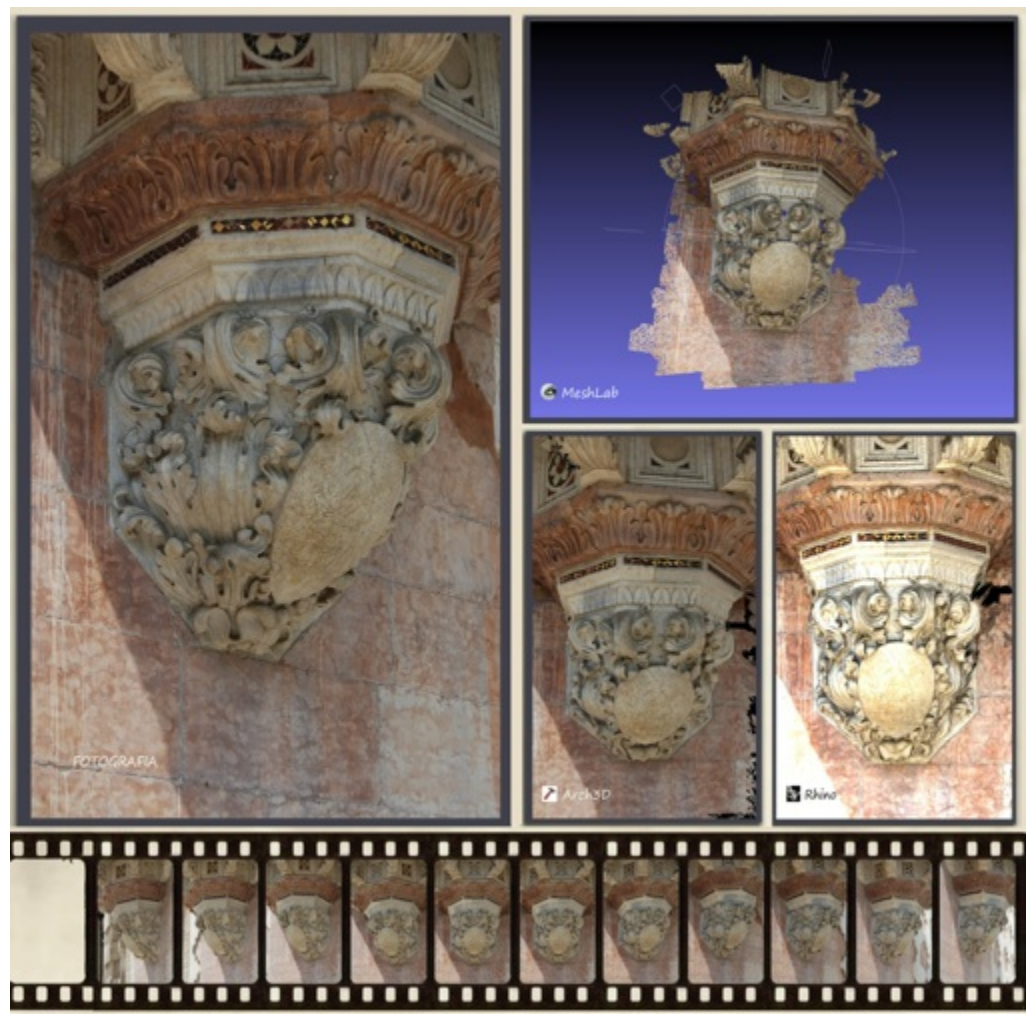

\section{Estereofotogrametria}

A estereofotogrametria é uma técnica mais sofisticada da fotogrametria (figura 3). Une o registro da realidade pela fotografia mais a projeção de uma cena tridimensional em um plano bidimensional. Com isso, esse método utiliza fotogramétricas baseadas na correspondência entre uma projeção em perspectiva e uma ortográfica, além de permitir que se estabeleça uma relação estreita entre o espaço da fotografia e o da representação. A partir desse modelo geométrico, de uma imagem conhecida, é possível saber a projeção de um ponto na cena, partindo do centro óptico da câmera e projetando-a até o infinito. Contudo, ao utilizar duas imagens da mesma cena, as coordenadas 3D podem ser recuperadas a partir da intersecção no espaço das projeções de dois pontos homólogos. A partir desses princípios, foram desenvolvidas as técnicas estereofotogramétricas (DE LUCA, 2009). 
Figura 3 - Representação da estereofotogrametria baseadas em imagens. (Fonte: DE LUCA, 2009).

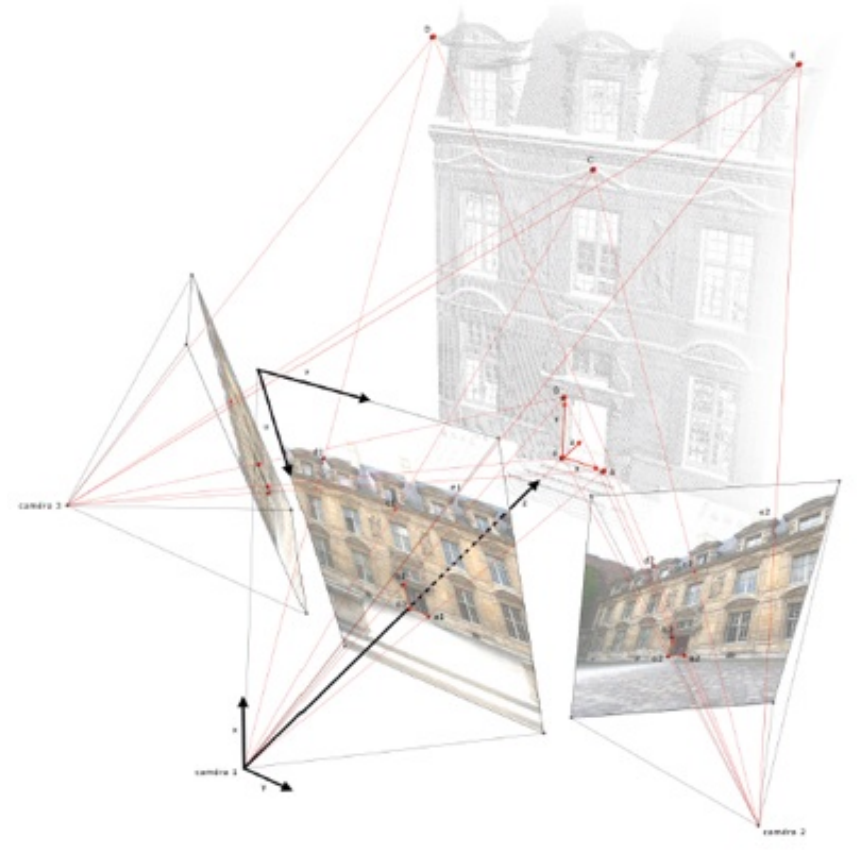

\section{Evolução da fotogrametria}

As três soluções supracitadas mostram a evolução da fotogrametria. Esses produtos fotogramétricos têm sido cada vez mais utilizados, principalmente, com a popularização dos drones, pela facilidade da aquisição de dados e quantidades de informações que as imagens aéreas e espaciais podem oferecer.

Entre as vantagens destes processos pode-se observar a possibilidade de realizar medições diretas de distâncias, áreas e ângulos, além de uma grande quantidade de informações, acarretando a melhoria da interpretação dos dados com um processo rápido. Porém, questões climáticas também podem ocasionar perda de informações. Outro ponto importante é a escolha da câmera fotográfica utilizada, pois influencia na qualidade geométrica da imagem. Em função dessas vantagens, vem crescendo sua utilização em diversos segmentos, principalmente, em função de projeto e áreas que necessitam de um planejamento maior e um acompanhamento constante, como: atualização do IPTU, projetos de irrigação e de oleodutos, entre outros.

\section{Escaneamento a laser 3D}

O escaneamento a laser 3D é uma tecnologia sem contato físico, que permite digitalizar ambientes muito complexos e detalhados. O equipamento capta as formas e contornos de objetos e edificações por meio de sensores baseados em ondas de luz laser para medição. Assim sendo, o escaneamento é feito devido à aquisição de milhares de coordenadas por segundo e pela criação de nuvens de pontos de dados da superfície reproduzida. Deste modo, é caracterizado como uma maneira de capturar um modelo do estado real de uma edificação 
histórica, de forma precisa e eficiente, dentro do contexto da computação, como uma representação digital tridimensional (PAMART, 2019).

A tecnologia de escaneamento a laser 3D se diferencia das outras ferramentas apresentadas quanto à velocidade de coleta de dados e o alto nível de detalhamento, com precisão milimétrica do processo de aquisição tridimensional. Além disso, o escaneamento a laser possui uma captura e extração automática da geração do modelo geométrico. Em contrapartida, outros meios apresentados que possuem um custo mais baixo, exigem que as informações coletadas sejam tratadas por um conjunto de softwares.

Faz-se importante ressaltar que todas as técnicas apresentadas são consideradas tecnologias e se integram para suprir as lacunas de cada levantamento e mapeamento. A possibilidade de agregar elementos arquitetônicos, fontes de dados com planos $2 \mathrm{D}$, fotografias e varreduras a laser $3 \mathrm{D}$, ou seja, informações de diferentes fontes, torna-os úteis para vários tipos de pesquisa e profissionais. Tendo em vista que o campo do patrimônio cultural é diverso e apresenta muitas especificidades, vale ressaltar que, quanto maior a integração entre essas tecnologias, maior será a sua capacidade de documentação, reconstrução digital, catalogação, intervenção, manutenção e potencial de uso de edifícios tombados existentes.

Dentro deste contexto, destaca-se a importância do inventário completo dessas edificações de valor cultural e histórico com um modelo tridimensional semântico, que funciona como um catalisador de informações de todo o ciclo de vida de um bem patrimonial. Esse inventário possibilita armazenar as diversas informações levantadas sobre os estilos formais, detalhes construtivos, histórico, iconografia, ou seja, tudo referente ao conhecimento do bem. Para isso, são utilizadas todas as ferramentas já supracitadas de levantamento, escaneamento e plataformas de softwares digitais, como o BIM.

Paralelamente às questões dos modelos de informações gerados da digitalização do patrimônio, pode-se ainda integrar aos modelos de experiências de realidade aumentada e realidade virtual. A implantação de sistemas com realidades e experiências entre o patrimônio e as tecnologias do ciberespaço acaba fortalecendo e valorizando a cultura e sua memória, principalmente por criar espaços dinâmicos que possibilitam criar novos aspectos socioculturais. Entretanto, é importante frisar que os sistemas computadorizados, assim como as tecnologias digitais, são formas de entender e construir centros de conhecimentos, mas não excluem as outras formas presenciais de experiências.

Por fim, como visto ao longo deste trabalho, o levantamento a partir da captura da realidade constitui o segundo passo para a modelagem de edificações históricas. Posteriormente serão incorporadas outras informações que permitirão o detalhamento de um modelo que sirva de referência para futuros estudos, intervenções, gestão e operação da edificação.

\section{Disseminação dos processos da conservação e restauro}

As discussões apresentadas até aqui, revelam as possibilidades da tecnologia digital para o desenvolvimento da área de conservação e restauro, com modelos cada vez mais fidedignos 
que permitem ampliar as possiblidades do patrimônio. Além disso, essas tecnologias facilitam o acesso às informações sobre os bens de interesse histórico e cultural por meio de iniciativas para registrar e compartilhar as facetas e palimpsestos dos edifícios históricos.

A digitalização da área patrimonial está cada vez mais abrangente, oferecendo à humanidade a oportunidade de ampliar o conceito de patrimônio e difundir as informações da herança cultural, principalmente pelo surgimento de novos métodos para identificação das informações e novos modos de documentação do patrimônio cultural. Como consequência, podem ser citados a construção de novas coleções virtuais, mapeamento de conceitos materiais e imateriais, interação entre diversos agentes sociais, auxílio em reconstituições, avaliações e criações de ambientes imersivos e transferência de todo o material produzido para um espaço virtual. Com este ambiente, é possível construir uma memória do mundo, com delimitações conceituais a partir de textos, imagens, sons, bem como a oportunidade de acessar essas informações, disponibilizadas em tempo real por um número cada vez mais amplo de profissionais que podem se apropriar, reformatar e devolver ao ciberespaço novas informações (DODEBEI, 2007).

A partir do exposto, entre as possibilidades oferecidas pela interação das tecnologias digitais com o estudo do patrimônio, estão a criação de registros documentais para a preservação da memória. Portanto, são utilizadas informações heterogêneas de dados qualitativos, quantitativos, aplicação de tecnologias diferentes com representações bidimensionais e tridimensionais para, então, fornecer um contexto histórico, de ciclo de vida, além de diversos materiais complementares de estudos para a disseminação e conhecimento dos bens patrimoniais. A divulgação do patrimônio a partir de plataformas virtuais em redes pode ser observada, conforme segue.

\section{Links}

O projeto Links é uma proposta ontológica dedicada ao monitoramento da conservação de igrejas em cantaria policromada. Trata-se, portanto, do desenvolvimento de plataformas digitais colaborativas a fim de produzir e compartilhar dados especializados e conhecimentos sobre objetos patrimoniais para restauração, conservação, ensino e pesquisa. A divisão destes dados e conhecimentos requer uma estrutura de $\mathrm{Tl}$ ad hoc formal, para facilitar seu uso em termos de aquisição, pesquisa e referências cruzadas. Este projeto em específico tem como foco a proposta de uma ontologia de domínio, dedicada à descrição dos fenômenos de degradação do material pétreo do patrimônio edificado alcançando, assim, um verdadeiro diálogo formal entre todos os recursos heterogêneos que descrevem a complexidade do edifício.

Formado, sobretudo, como um modelo conceitual que visa a constituição de um ambiente digital para a descrição do estado de conservação de monumentos históricos, por meio da interligação de descritivos qualitativos, quantitativos, correlações espaciais, morfológicas e semântica de conjuntos de dados integrados por múltiplos agente, de acordo com os níveis de leitura. 
Esse projeto pretende reunir nesta plataforma os dados multidisciplinares recolhidos por todas as equipes envolvidas, de forma a se tornar um instrumento que permita comparar igrejas entre si, sob um ponto de vista histórico, artístico e o acompanhamento do seu estado de conservação.

\section{CNCA}

O projeto CNCA, é uma iniciativa que tem como objetivo a promoção e disseminação da cultura do design arquitetônico digital a um público diversificado. Para isso, criou-se uma plataforma com intuito de divulgar e oferecer chamadas de contribuições que permitem o desenvolvimento de reflexões teóricas e práticas, para pensar, conhecer e auxiliar o design digital. A fim de promover a plataforma, serão lançados caminhos de pesquisa que ainda não foram explorados pelo grupo francês de pesquisadores, mas já está sendo analisado para a condução deste artigo. As contribuições assumirão a forma de artigos de pesquisa, artigos de opinião, estudos de caso ou feedback, apresentados por pesquisadores, professores, arquitetos e alunos. As reflexões, que emanam destes diversos documentos, serão divulgadas no espaço virtual em formatos acessíveis.

\section{IPERION HS}

O projeto IPERION HS visa estabelecer e operar uma plataforma integrada para a infraestrutura de pesquisas pan-europeias, para a instauração de pesquisas nacionais importantes e de reconhecida excelência na ciência do patrimônio. A ciência do patrimônio é um domínio científico jovem e transversal que abrange uma ampla gama de disciplinas de pesquisa, permitindo uma compreensão mais profunda do passado e um cuidado com o futuro do patrimônio.

O plano da IPERION HS está direcionado para uma abordagem científica unificada dos instrumentos europeus mais avançados para a análise, interpretação, preservação, documentação e gestão de objetos patrimoniais nos campos da história da arte, conservação, arqueologia e paleontologia. A atividade principal do projeto será oferecer acesso transnacional a uma ampla gama de instrumentos científicos de alto nível, metodologias, dados e ferramentas para o avanço do conhecimento e inovação no domínio.

\section{AIOLI}

O projeto AIOLI consiste em uma plataforma colaborativa que visa reunir as pessoas envolvidas na documentação, salvaguarda e compartilhamento do patrimônio cultural por meio de práticas que desenvolvam uma compreensão dos objetos patrimoniais. Para abastecer o programa com informações, é necessário um conjunto de profissionais, como: arqueólogos, arquitetos, engenheiros, especialistas em materiais, curadores, conservadores-restauradores, professores, estudantes e turistas.

Essa plataforma colaborativa permite que, a partir de fotografias, o aplicativo gere uma representação tridimensional do objeto selecionado, possibilitando que o mesmo seja 
enriquecido com anotações semânticas, adição de recursos textuais, imagéticos e sonoros. A integração das tecnologias permite que se desenvolva nesse projeto a democratização das técnicas de fotogrametria para produzir modelos 3D, além de possibilitar um grande compartilhamento de dados recolhidos por intermédio da nuvem. Esta ferramenta tem seus objetivos ancorados no desenvolvimento de uma ciência cidadã, pois cria novas metodologias de trabalho multidisciplinar e propõe novos cenários de análise comparativa e cooperativa de objetos patrimoniais.

As experiências de compartilhamento e disseminação de informações especializados apresentados são exemplos do constante desenvolvimento e popularização de pesquisas e capacitação de profissionais da área do patrimônio do grupo francês estudado. Por se apropriar da cibercultura, viabiliza a elaboração de plataformas com capacidade de processamento e armazenamento de dados capazes de promover e democratizar a difusão da informação da herança cultural.

\section{Considerações finais}

Este artigo apresentou as principais possibilidades oferecidas pelas tecnologias digitais na área da conservação e restauração de patrimônio cultural, considerando a plataforma do grupo de pesquisa francês UMR 3495 CNRS / MC MAP. Integrando várias áreas de conhecimento, profissionais e instituições, tanto na área de educação, quanto com instituições públicas de pesquisa e cultura, mostrou-se como um laboratório de grande produção intelectual e de inovação na área de patrimônios.

Os processos científicos de documentação, reconstrução digital e catalogação que foram apresentados são instrumentos que modificam a forma como são geradas as informações a respeito do levantamento, mapeamento e diagnóstico arquitetônico principalmente, a partir da rapidez do processo de captura e tratamento das imagens e representações tridimensionais. Com isso, possibilita um maior aprofundamento e estudos sobre o patrimônio construído, além de potencializar os repertórios de dados e a gestão de conservação e manutenção das edificações.

Finalmente, a digitalização do patrimônio por meio de plataformas colaborativas aproxima a informação de diferentes usuários e profissionais oportunizando, assim, a ampliação dos conceitos referentes ao patrimônio e à difusão das informações da herança cultural. $O$ surgimento de novos métodos para identificação das informações e novos modos de documentação e compartilhamento do patrimônio cultural também merecem destaque.

Vale salientar que as proposições e contextos apresentados nesse trabalho não condizem com a realidade do patrimônio e dos profissionais brasileiros. As equipes e obras de conservação e restauro ainda não acompanham o desenvolvimento e o avanço das possibilidades oferecidas pelas inovações. Observa-se uma desconformidade com o que tem sido absorvido pelos profissionais, empresas e órgãos de preservação pela forma como os bens patrimoniais são tratados no Brasil - sempre de maneira incipiente, desatenta, sem seus devidos cuidados, sem organização e ausência de investimento. Portanto, percebe-se um 
reflexo da falta de conhecimento e interesse na preservação da história das comunidades e suas várias formas de manifestação.

As alternativas apresentadas neste trabalho não tiveram a intenção de esgotar o tema, que permanece em evolução, mas, sim, oferecer trilhas de pesquisas diante da rede de informações da cibercultura, além de exibir as principais possibilidades aos profissionais e pesquisadores interessados em dar visibilidade e sistematização à vasta ruína de mensagens que compõem o patrimônio.

\section{Referências}

ABRANTES, Andreza. Tecnologias digitais como instrumentos de preservação do patrimônio urbano edificado. Dissertação do Curso de Mestrado profissional do Instituto do Patrimônio Histórico e Artístico Nacional. Rio de Janeiro, 2014.

AZEVEDO, Sandro. Semiótica e realidade aumentada: enunciação, tecnologia, publicidade. Curitiba: Appris, 2020.

CANUTO, Cristiane; SALGADO, Monica. Modelagem da informação da construção na preservação da arquitetura moderna. In: ENCONTRO NACIONAL DE TECNOLOGIA DO AMBIENTE CONSTRUÍDO, 16., 2016, São Paulo. Anais ... Porto Alegre: ANTAC, 2016.

CANUTO, Cristiane; MOURA, Larissa; SALGADO, Mônica. Tecnologias digitais e preservação do patrimônio arquitetônico: explorando alternativas. PARC - Pesquisa em arquitetura e construção, Campinas - SP, v. 7, n. 4, p. 252-264, dezembro de 2016.

DE LUCA, Livio. Survey, modeling and representation based on architectural images: methodological reflections and research trails. MAP-Gamsau, Portal of Archtectural Imagebased-modeling. 2009. Disponível em: //www.gamsau.map.cnrs.fr/aibm/Portal_of_ Architectural_Image-Based-Modeling/Article-DeLuca2.html . Acesso em: 20 de nov. de 2020.

DODEBEI, Vera. Digitalização do patrimônio e organização do conhecimento. VIII ENANCIB Encontro nacional de pesquisa em ciência da informação. Salvador, Bahia, outubro de 2007.

FARIAS, Vanessa. Plataforma BIM exigência pelo governo federal inicia em 2021. Buildin: construção e informação, 2019. Disponível em: https://www.buildin.com.br/plataforma-bim/. Acesso em: 20 de nov. de 2020.

FILIPPUCCI, Marco. Drawing and surveying with pixels: photo modeling with free software for architectural survey. Portal of Archtectural Image-based-modeling. 2011. Disponivel em: http://www.gamsau.map.cnrs.fr/aibm/Portal_of_Architectural_Image-Based-Modeling/ArticleFilippucci.html. Acesso em: 20 de nov. de 2020.

IPHAN. Carta do Restauro, 1972. Ministério de instrução pública (Governo da Itália). Circular n. 117. Disponível em: http://portal.iphan.gov.br/uploads/ckfinder/arquivos/Carta\%20do\%20 Restauro\%201972.pdf. Acesso em: 20 de nov. de 2020.

LEMOS, André. Cibercultura, tecnologia e vida social na cultura contemporânea. Porto Alegre: Sulina, 2002.

LÉVY, Pierre. Cibercultura. São Paulo: Ed. 34, 2000. 
PAMART, Anthony. Recommandations du consortium 3D SHS: synthèse des outils des Technologies 3D. CNRS, MAP - UMR 3495, 2019. Disponível em: https://hal.archivesouvertes.fr/hal-02159453/document. Acesso em: 20 de nov. de 2020.

SANTAELLA, Lucia. Culturas e artes do pós-humano: da cultura das mídias à cibercultura. São Paulo: Paulus, 2003.

\section{Sobre os autores}

Laís Soares Pereira Simon, Ma., UDESC, Brasil, <lalisoaresp@gmail.com> Alexandre Amorim dos Reis, Dr., UDESC, Brasil, <alexandre.a.reis@gmail.com>

Flávio Anthero Nunes Vianna dos Santos, Dr., UDESC, Brasil, <flavio.santos@udesc.br> 